JOURNAL OF SECURITY AND SUSTAINABILITY ISSUES

ISSN 2029-7017 print/ISSN 2029-7025 online

2019 December Volume 9 Number 2

http://doi.org/10.9770/jssi.2019.9.2(10)

\title{
Scopus
}

\section{DOES THE ELECTRICITY CONSUMPTION DETERMINE THE ECONOMIC GROWTH AND ENERGY PRICES IN ASEAN COUNTRIES?}

\author{
Yusro Hakimah ${ }^{1}$, Andhyka Tyaz Nugraha ${ }^{2}$, Andi Surya ${ }^{3}$, \\ Armalia Reny Wijayanti Ananda ${ }^{4}$, Pudji Astuty ${ }^{5}$ \\ ${ }^{1}$ Faculty of Electrical Engineering, Universitas Tridinanti Palembang, Palembang, Indonesia \\ ${ }^{2}$ School of Technology Management and Logistics, College of Business, Universiti Utara Malaysia, Sintok, Malaysia \\ ${ }^{3,4}$ Faculty of Business, Universitas Mitra Indonesia, Bandar Lampung, Indonesia \\ ${ }^{5}$ Faculty of Economics, Universitas Borobudur, Jakarta, Indonesia \\ E-mails: ${ }^{1} y u s r o h a k i m a h @ y a h o o . c o . i d,{ }^{2} a n d h y k a @ s t u d e n t . u u m . e d u . m y,{ }^{3} a n d i s a n g s u r y a @ u m i t r a . a c . i d$, \\ ${ }^{4}$ armalia.reni@umitra.ac.id, ${ }^{5}$ pudji_astuty@borobudur.ac.id
}

Received 17 March 2019; accepted 30 September 2019; published 15 Decemeber 2019

\begin{abstract}
The general objective of this study is to estimate the relationship between electricity consumption, economic performance and the price of electricity in four sectors namely the industrial, commercial, mining and agricultural by using the panel data approach on leading ASEAN countries. The present study intends to contribute significantly to the existing literature by presenting a comprehensive approach of the issue of electricity consumption in Thailand. The information of electricity consumption in the industrial, commercial, agricultural and mining sectors is essential to understand the magnitude of the sectors' sensitivity to change with respect to GDP and electricity price. Moreover, real electricity price is incorporated in this study to provide a more consistent result. The findings are important for researchers and academicians by providing a better knowledge of sectoral electricity demand to permit better regulatory decisions in order to facilitate economic efficiency. Apparently for the policy makers, it will be possible that the approach of this study could be useful as a guideline to facilitate the adoption of a more appropriate model for electricity demand management as well as restructuring the electricity sectors. Furthermore, the findings of this study will be helpful in the formulation of effective energy and pricing policies in order to encourage consumers towards the efficient use of energy for the future of sustainable energy and development.
\end{abstract}

Keywords: electricity consumption; economic growth; energy prices

Reference to this paper should be made as follows: Hakimah, Y., Nugraha, A.T., Surya, A., Ananda, A.R.W., Astuty, P. 2019. Does the electricity consumption determine the economic growth and energy prices in ASEAN countries?, Journal of Security and Sustainability Issues 9(2): 489-503. http://doi.org/10.9770/jssi.2019.9.2(10)

JEL Classifications: F23, K32

\section{Introduction}

Electricity is a man-made source of energy. As it is non-durable, electricity compliments durable goods like electrical appliances or electrical machinery (Mohd Hafiz Aswad, 2015; Vlasov \& Kiseleva, 2017). It helps directly by running consumer durables in terms of services and running machines which help directly or indirectly to produce consumer goods. Electricity is an exceptional energy because the consumption of electricity has to be simultaneous once it is been generated, thus electricity cannot be economically stored. Furthermore, electricity has a unique position among other different types of energy because electricity is clean energy, is easy to transfer and can be transformed into other kinds of energy. The demand of electricity varies hourly, daily, weekly and across the seasons and industries and societies and is determined by wide arrow of factors (Strielkowski et al., 2017; Tvaronavičienė et al., 2017; Melas, et al., 2017; Supian \& Ab, 2018; Kuiken \& Más, 2019; Todorov et al., 2019; Dudin et al., 2019; Vlasov et al. 2019; Smaliukiené, Monni, 2019; Rezk et al., 2018; 
Rogalev et al., 2018).

It cannot be fully controlled, and it is practically impossible to prevent market participants from consuming more or less electricity.

Electricity plays an important role in the process of economic growth and is required for both commercial and non-commercial usage. Commercial usage of electricity refers to the use of electric power in the industrial, commercial, mining and agricultural sectors. For non-commercial, the principal use of electricity energy is for public lighting and by residential consumer. Feron (2016) stated that electricity is is indispensable to industrial and commercial establishments, meaning that a lack of energy causes difficulties and economic losses due to the reduction in production (Panos, Densing, \& Volkart, 2016). Moreover, an increase in the production of goods and services will consume a lot of electricity. Therefore, the demand for electricity is driven by such important factors as industrial development, population growth, urbanization and the rising standard of living. This is why electricity has become the principal type of energy source to improve the socioeconomic condition in countries (Widiastuti, et al., 2017; Buyinza \& Kapeller, 2018).

The increasing trend of electricity consumption (ECN) and its relationship with the growing economy has come to the special attention of policy makers. In Thailand, electricity demand (ELCD) is mostly met with the use of insufficient and expensive fuel resources such as natural gas and coal which continues to expand rapidly. At the same time, it is the government's responsibility to supply a sustainable and economical price of electricity to consumers. However, the lack of sufficient generation to meet the increasing demand for electricity in the country will lead to undesired political, social and economic effects. Therefore, an understanding of consumers' demand behavior on electricity is important in order to have an accurate planning for the sufficient supply of electricity commensurate with this demand. Furthermore, it is vital to have comprehensive knowledge of factors that influence ECN. This information could be useful for policy makers to come out with better energy policies and strategies to minimize the socioeconomic effects such as their impact on firms, households, and consequently, social welfare.

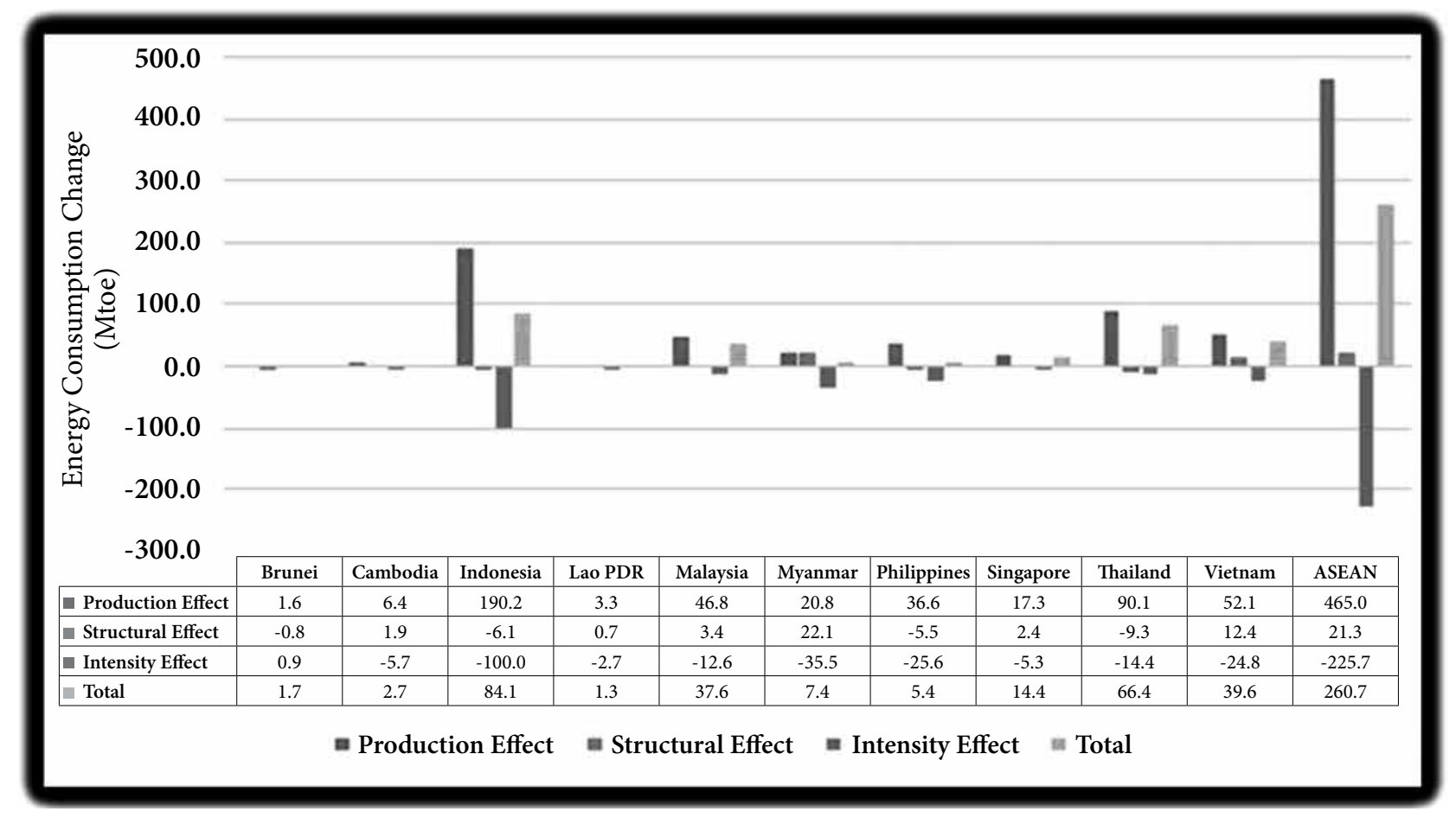

Figure 1. Energy consumption in ASEAN economies 
The demand for electricity in Thailand is primarily for the industrial, commercial, residential, public lighting, mining and agricultural sectors. The factors that derive ELCD differ across the economic sectors. For instance, the industrial and commercial sectors consume electricity as an input of production and their objective is to minimize the cost of production. Residential consumers' demand for electricity relies on consumers' utility maximization by allocating income so that they obtain great satisfaction from total expenditure. The industrial sector is the main electricity consumer, accounting for more than 40 percent of total ECN in Thailand. The commercial sector is the second largest electricity consumer at just below 35 percent, followed by the residential sector at around 20 percent. By comparison, other sectors such as public lighting, and the agricultural and mining sectors made up less than two percent of total ECN. To investigate the behaviour of electricity consumers among the sectors, this study will emphasize the commercial usage of electricity referring to the four key sectors in Thailand's economy, namely the industrial, commercial, mining and agricultural sectors. These sectors contribute significantly to the development of Thailand's economy in terms of GDP and use electricity energy as an input to produce goods and services. Meanwhile, other sectors such as residential and public lighting are not considered in this analysis because these sectors consume electricity for non-commercial purposes and do not contribute to the country's GDP.

The industrial sector can be defined as a consumer engaging in the manufacturing of goods and products. The industrial sector represents both the manufacturing and construction sectors. The chemical, base metal, paper, wood, non-metal and food industries are the most energy-intensive users in the industrial sector (Diawuo, Baptista, \& Silva, 2018). Overall energy use in this sector is largely for processing heat, cooling and powering machinery. It is found that that the industrial sector has the largest share of electricity usage in overall ECN but its share slowly reduce from 51 percent to 43 percent between the period 2002 and 2012. It can be observed that in the future, electricity consumed by the industrial sector will not only decrease but could also diminish. The reason could be from the energy efficiency measures that were implemented by industrial consumers, which managed to reduce the energy demand (National Energy Balance, 2012). Meanwhile, industrial ECN has recorded a 6.9 percent growth from 2002 to 2012. One of the main reasons for the higher growth was due to the performance of the GDP growth rate in the construction sector that is driven mostly by energy intensive industries (National Energy Balance, 2012).

In order to understand the efficiency of electricity usage relatively to the performance of the economy, this study uses the term energy intensity as a measurement for the quantity of energy required per unit of economic output or GDP. The industrial sector recorded the highest electricity intensity compared to other sectors in the economy. Industrial electricity intensity slowly decreased by 8.4 percent from 2005 to 2012 .The commercial sector is defined as a consumer occupying or operating in the buildings used by businesses or wide range of facilities such as government buildings, religious organizations and any other forms of businesses or commercial activities which are Industrial Commercial Mining Agricultural not primarily involved in manufacturing, quarrying or mining activities. According to the total number of electricity consumers, the commercial sector is the second largest consumers after the residential sector, accounting for 1.5 million or 17 percent of the total electricity consumers in 2012.

The mining sector can be defined as a consumer using most part of the electricity for extracting minerals and dredging activities for crude oil, natural gas and tin. This sector contributed the lowest share of total ECN at 0.1 percent. The electricity consumed by the mining sector declined from 2002 until 2008, but then it slowly increased beginning in 2010. Moreover, the mining sector's contribution to GDP growth also started to decline within the same period due to lower production of crude oil ans mining sector's electricity intensity pattern displayed at almost a constant trend between $0.17 \mathrm{GWh}$ and $0.15 \mathrm{GWh}$ from 2002 until 2012.

The agricultural sector is a consumer conducting specific agricultural activities strictly related to agricultural cultivation and breeding. Electricity used in the agricultural sector is used mainly to operate machinery and equipment, heating or cooling green houses, lighting in the farms, water pumping for the irrigation of land and controlling water gates for the production of grains. In comparison to other sectors in the economy, the agricultural sector has become increasingly dependent on energy resources. This sector was relying more on petrol 
and the coal industry output as its input compared to electricity and natural gas (Commander, Nikoloski, \& Vagliasindi, 2015; Swenson, 2016). It is observed that the agricultural sector only contributes a smaller share of the total ECN, accounting for less than 0.5 percent. As depicted in electricity consumed by the agricultural sector increased from one GWh to 344 GWh from 2002 until 2012. The growth in ECN is in line with the GDP growth rate in the agricultural sector during the same period. As a result, agricultural electricity intensity has gradually increased from 2002 to 2012 reaching at $0.63 \mathrm{GWh}$.

Hence, this study aims to shed light on the modelling ECN, namely the industrial, commercial, mining and agricultural sectors to present empirical evidence on the elasticity and causality in Thailand. To provide a reliable sectoral ECN model, the above-mentioned variables such as sectoral GDP and real electricity price will be applied. The key contribution of this study is to provide some information on the responsiveness of ECN toward the changes in economic performance and electricity price in sectoral level. Another contribution is to investigate any potential causal relationship between ECN with economic performance and electricity price where the results would be useful for a recommendation of energy policies.

The general objective of this study is to estimate the relationship between ECN, economic performance and the price of electricity in four sectors namely the industrial, commercial, mining and agricultural by using the panel data approach. The present study intends to contribute significantly to the existing literature by presenting a comprehensive approach of the issue of ECN in Thailand. The information of ECN in the industrial, commercial, agricultural and mining sectors is essential to understand the magnitude of the sectors' sensitivity to change with respect to GDP and electricity price. Moreover, real electricity price is incorporated in this study to provide a more consistent result. The findings are important for researchers and academicians by providing a better knowledge of sectoral ELCD to permit better regulatory decisions in order to facilitate economic efficiency. Apparently for the policy makers, it will be possible that the approach of this study could be useful as a guideline to facilitate the adoption of a more appropriate model for ELCD management as well as restructuring the electricity sectors. Furthermore, the findings of this study will be helpful in the formulation of effective energy and pricing policies in order to encourage consumers towards the efficient use of energy for the future of sustainable energy and development.

\section{Theoretical Review}

Electricity can be referred to as derived demand because electricity is a function of the types of electrical appliances that exist in a particular type of dwelling or building. In this context, electricity is derived along with other inputs for a factor of production resulting from the demand of other intermediate goods or services. Inglesi-Lotz (2019) stated that there were two approaches in dealing with ECN based on the economic perspective. The first approach was from the supply side where electrical energy is used as an input for the production output of the sector. However, the results from the regression analysis were found to be insignificant and it was concluded that ECN was not an appropriate factor to explain the output trends of the sectors. The second approach was from the demand side where consumers used electrical energy as a result of the output and prices. Based on this approach, it was suggested that ECN from the demand side was appropriate in analyzing the ECN model. This means that consumers' ECN was a function of electricity price and the total output produced in each sector.

The rationale of behaviour of consumers on the demand of electricity is based on different theoretical foundations. A small number of theories have been proposed to explain the diverse cause of ELCD in order to have a better understanding of the factors that influence the demand for electricity. Although the articles, such as Cialani and Mortazavi (2018) and Bajjali and Shamayleh (2018) cover a variety of theories, this review will focus on the seven most important factors that influence the demand for electricity, which emerge repeatly throughout the literature reviewed. These factors are price of electricity, income or GDP, price of substitute energy, population, weather, stock of electrical appliances and the number of consumers. To achieve the objective, this study will primarily focus on the application of price of electricity and GDP. 
Here it has to be noted that oil prices affect various facets of economics, not only demand for energy (Masood et al., 2019; Humbatova et al., 2019).

The consumption of energy is mainly determined by its own price. Caldara, Cavallo, and Iacoviello (2019), in his study on crude oil demand, has claimed that the price elasticity of demand for energy was important for policy makers to monitor the quantity of energy demand. He suggested that the price of elasticity was very low in the long and short run that was derived from a variety of econometric procedures and covered different periods. Meanwhile, Foster, Wagner, and Liebman (2015) analyzed the price elasticity of natural gas and they argued that the fluctuation in natural gas price had a significant effect on consumers' change in their fuel demand. On behalf of ECN, the price of electricity or electrical tariff is commonly used to determine the quantity of electricity usage. According to the law of demand, the price of electricity is assumed to have an inverse relationship to the quantity demanded for electricity. Therefore, in the function of ECN, electricity price plays an important component due to its greater influence on affecting the quantity of electricity consumed. The majority of the articles on ECN analysis such as Polemis (2016) and Labandeira, Labeaga, and López-Otero (2017), concluded that a higher electricity price would cause a substantial reduction in overall ECN, while a falling in electricity price would increase the usage of electricity, ceteris paribus. For instance, when the price of electricity increases, it increases the total cost of production. In order to lessen the cost of production, a firm will reduce the purchase of electricity energy. As a result, the firm's demand for electricity will decrease.

Recent study outlined, who focused on commercial and industrial water demand, argued that the demand for energy did not only depend on the price of energy, but was also influenced by the sector performances. In general, the majority of economic articles on ECN such as Bajjali and Shamayleh (2018) and Javid and Qayyum (2014); Wonyra, (2018) have considered the relationship between electricity and the economic performance or income based on GDP. In particular, as economic development progresses, consumption and production patterns will change, thus resulting in changes in energy use patterns. Most articles on ELCD, such as Bajjali and Shamayleh (2018), have observed that an increase in GDP will lead to an increase in ELCD. For instance, an increase in GDP will raise consumer wealth, thus consumers get an extra income to spend. Thereby, it raises more consumption for the quantity of goods and services. These structural changes in consumption result in changes in production. In other words, when the demand for goods increases, firms will raise the production and this will promote changes in ECN. This means that more additional electricity is required in order to produce more output.

According to the sectoral or firm perspective, electricity is an essential input for the production process of goods and services, similar to labour and capital. As explained by Debnath and Mourshed (2018), in order to produce a unit of product, a firm needs an input factor in the form of electricity. Thus, ELCD adds to the production function. Generally, the objective of the firm is to maximize profit or to minimize cost for a given level of outputs. For instance, the profit maximizing firm will choose both input and output with the sole goal of maximizing economic profits that refer to the difference between total revenue and total cost.. Several studies on industrial ELCD, such as Zafarullah, (2018); Krutsyak (2019) and Tishler (1983), applied the producer of profit maximization theory.

In comparison, cost minimization is an alternative way considering the behaviour of a profit maximizing firm that takes factor prices as given but can influence output prices. According to Medlock III, a firm purchases energy as an input to the production of its output and naturally attempts to do it in accordance with cost minimization. Another study by Ali (2016) used the cost minimization model on ECN function. In this model, the authors considered production as a function of energy services, including the service of electricity and other kinds of energy as well as the service of other production factors such as labour and capital. Furthermore, electricity service was considered as a function of ECN and the quality of electricity supply. The production cost subject to the production function constraint was minimized and ECN of an individual firm was introduced as a function of the electricity supply quality, electricity price, price of substitute energy and the firm's value added. Recently, Mohd Hafiz Aswad (2015) analyzed the demand behaviour of ECN in different sectors in Iran. Based on the article by Sani, Mukhtar, and Gani (2017), he described the concept of cost minimization of production 
cost was subject to the production function constraint. In his study, he claimed that the production by the industrial and agricultural sectors was considered to be a function of ELCD for an input together with other inputs in the production process (Maree, 2017; Margaret \& Donna, 2017). As a result, the basis of the quantity of ECN was derived as a function of output of the industry, the price of electricity, the price of substitute fuel, labour and other exogenous factors. In addition, the author also included the stock of electrical appliances and technological progress as proxied by fixed capital to investigate the impact on the level of sectors. In other studies, some researchers, such as Hassan (2018), have also considered the cost minimization theory in their ECN modelling.

The study on consumers' behaviour on ECN is importantly needed in order to understand the causes that determine the change in the consumption of electricity. The importance of this study hinges on exploring two main factors such as economic performance and electricity price elasticity. This illustrates some information as how ECN changes due to the impact of economic performance and electricity price. Furthermore, there is also a causal relationship between ECN, economic performance and electricity price.

\subsection{Relationship between ECN and Economic Performance}

Generally, GDP is the most commonly used variable as an indicator for measuring economic growth or national income in determining ECN of the respective country. However, other ELCD studies that specifically focus on sectoral levels also employed GDP as an indicator to represent the sector income or economic performance. For the purpose of this review, the terms of income, economic performance or economic growth are used interchangeably with GDP in order to explain its relationship with ECN In theory, the demand for normal goods should increase proportionately when there is an increase in income. As for energy, the measurement of income effects on consumption is important because energy bills often represent a lower proportion of income for higher income consumers (Null, 2018). In energy literature, the estimation of income elasticity for ECN began with the study by $\mathrm{Su}$ (2019) in the United Kingdom (UK). He was concerned with the response of consumers towards changes in income. The results revealed the stability in his ELCD function and it indicated that ELCD in the UK was sensitive to changes in economic performance. Following his introductory study, research efforts on the estimation of income elasticity have become extensive and have raised the attention of analysts and researchers. For instance, several articles (Boogen, Datta, \& Filippini, 2017; Mensah, Marbuah, \& Amoah, 2016) used national income to estimate the ECN in their respective countries. Based on their investigations, the estimation of income elasticity was universally significant and indicated a positive sign towards the change in ECN. However, the level of income elasticity showed varying outcomes. Boogen et al. (2017) measured the determinants of Greek ECN from 1961 to 1986. They found that the income elasticity was elastic at 1.56. In the same Omojolaibi, Mesagan, and Oladipupo (2016) found similar findings of ELCD in the Gulf Cooperation Council (GCC) member states,. The outcomes indicated that the long run elasticity of income between GCC countries was very elastic, and varied from 1.65 to 5.39. Moreover, Dai and Gao (2016) also found consistent results for ELCD in Sri Lanka covering the period from 1970 to 2003. The income elasticity had a range of between 1.00 and 1.96 .

Several researchers discovered that ECN was actually less sensitive to changes in income in the long run (Haseeb et al., 2019). Akarsu (2017) examined the influence of GDP on ECN in South Africa over the period from 1950 to 1983 . He revealed that the income elasticity was inelastic as estimated at 0.71 . In another study, R. Inglesi-Lotz and Pouris (2016) also found consistent results regarding the inelasticity of income. Based on per capita studies over the period from 1978 to 2005, he concluded that ECN of South Africa was driven by GDP as estimated at 0.31. Meanwhile, studied ELCD of the United States and they concluded that the income elasticity was close to 0.5. Moreover, a study on the effect of GDP on ELCD in Namibia from 1960 to 2002. In this study, they reached the same conclusion that ECN was actually driven by income, where the elasticity was found to be inelastic at 0.59 .

Recently, Atalla and Hunt (2016) tried to investigate ECN in Turkey as a function of GDP. Atalla and Hunt (2016) estimated the income elasticity over the period from 1960 until 2008. The findings indicated that ECN tended to be very inelastic due to the change in income as calculated to be 0.17 . The results, reflecting the na- 
ture of the demand for electricity was similar to those reported. The authors used different time periods from 1970 to 2009 and the estimation of income elasticity was found to be 0.92. By making the comparison, it can be concluded that ECN in Turkey was less responsive to changes in GDP. Based on the findings from previous articles, there were similarities between the positive responses of ECN and the changes in income in the long run. However, the results also indicated that ECN had shown different sensitivities to income changes in their respective countries. For example, Atalla and Hunt (2016) found that the income elasticity was lower than unity in the long run, whereas the study of Boogen et al. (2017) presented that income elasticity ranged from 1.56 to 5.39. This suggested that ELCD was responsive to variations in income in the long run. Income level, often used as a proxy for GDP was the most important determinant of ELCD.

\subsection{Relationship between ECN and Electricity Price}

In theory, electricity price elasticity can be measured by unit changes in ECN with respect to unit changes in electricity price. However, there was a wide variation in the electricity price specifications reported in the literature. For instance, classical studies on electricity price elasticity such as categorized the related works by residential and industry between 1946 and 1957. For ELCD function, average revenue was used to represent electricity price. It was found that electricity price had little effect on long run ELCD. The price elasticity was ranged from -0.22 to -0.99 . In another study, author used the same average revenue to address ELCD in the United States (US), incorporating the use of pooled data of 48 states from 1961 to 1969 . He concluded that ELCD was responsive to change in electricity price as calculated from -1.09 to -1.14 . Within the same country, employed typical bills based on 500 kilowatt hours per month to represent electricity price in their cross section studies in 77 cities and 50 states. Both authors came up with the findings that electricity price elasticity ranged from -0.84 to -1.33 .

Recent studies by Ngondya (2018) and Ivy-Yap and Bekhet (2014) estimated the demand for electricity focused in developing countries. For instance, Ngondya (2018) studied the ECN in 32 developing countries from the 1999 until 2004 period. He employed price of oil as a proxy for the price of electricity due to difficulties to get data information. He argued that electricity price was actually dependent on oil price and indicated that electricity price would increase when there was an increase in oil price. Therefore, the estimation coefficient of electricity price elasticity in developing countries was found to be inelastic at -0.036 . However, the result was found to be biased because the price of oil could not explain the level of ECN more precisely to measure consumers' response to a change in price. Therefore, Ngondya (2018) suggested that the application of real electricity price would provide more accurate and appropriate results. In another study, employed the real electricity price to estimate the ELCD in India over the period from 1959 to 1995. As a result, they found that the price elasticity in the long run was inelastic, as estimated at -0.16 . Recently, used electricity price per capita to measure ECN between 1979 and 2008. However, the model suggested that the price elasticity was found to be insignificant to explain the electricity usage in Thailand.

In Thailand, academic studies about ECN are rare, with Ivy-Yap and Bekhet (2014) being among the main contributors. Scholar examined rural and urban ECN using annual data from 1980 until 2009. In these studies, they employed the CPI as a proxy for electricity price. The results showed that the electricity price elasticity was found to be insignificant as estimated at 0.59 . This means that the price of electricity failed to explain the ELCD both in rural and urban areas. In the same vein, Ivy-Yap and Bekhet (2014) examined the residential ECN from 1978 to 2011. Similar, they used the CPI as a proxy for electricity price. The results were also found to be insignificant where the price elasticity was estimated at -0.13 . However, both findings were inaccurate because the CPI was used as a proxy for electricity price which could lead the results to be insignificant. According to Author, one of the main issues associated with the CPI was that it was actually a fixed quantity price index based on sample prices rather than relative quantities purchased by consumers. In another study, Gillingham, Rapson, and Wagner (2016) estimated the short and long run ELCD in Sri Lanka based on annual data from 1960 to 2007. In the study, they employed an average price of electricity as one of the main determinants. The long run and short run price elasticities were found to be inelastic as estimated at -0.62 and -0.16 respectively. Moreover, also applied the same price specification to explain the ECN in South Africa covering the period from 1980 to 
2005. The result indicated that ELCD was less responsive to changes in electricity price in the long run as estimated to be at -0.56 . According to Acuña (2017), the average electricity price was the right indication and was statistically significant. They suggested that the average electricity price should be used in the ELCD function.

For causality analysis, very small number of studies such as Gillingham et al. (2016) investigated the relationship between energy and ECN together with its own price. For instance, author investigated the relationship between energy consumption and energy prices in four Asian countries. He discovered that there was a significant long run relationship running from energy price to energy consumption in Indonesia and Thailand, but no relationship was discovered in India and the Philippines. Meanwhile, Gillingham et al. (2016) found bidirectional causality between ECN and electricity price in Sri Lanka. In Thailand, Tasnim and Amin (2018) discovered unidirectional causality running from ECN to electricity price. They claimed that an increase in the consumption of electricity would cause inflation which would lead to a reduction in consumer purchasing power.

Based on the above reviews, all estimated electricity price parameters have the expected sign .The majority of the studies, such as Gillingham et al. (2016), concluded that electricity price had a negative relationship with ECN in the long run. However, the estimated price elasticity lay within a wide range of between -1.33 and -0.036 . On the other hand, there were mixed results in terms of causality relationship between energy, electricity and its own price.

\subsection{Relationship between ECN and Other Variables}

The demand for electricity commodity is not always explained by its own price and income, but it is also influenced by other potential factors that significantly affect ECN. These factors could be from the population, number of customers, electrical appliances, substitute price of energy and weather depending on the nature of the electricity commodity. Recently, empirical studies, such as Bajjali and Shamayleh (2018) Tasnim and Amin (2018) had considered other different explanatory variables to explain the aggregate level and sectoral ECN. For instance, scholar considered population as a determinant of ECN in Thailand. The results of the study revealed the positive elasticity in population as estimated at 0.89 . This implied that a higher population would constitute a major driver for ELCD in Thailand. In another study, Tasnim and Amin (2018) discovered the positive relationship between population and ECN especially in urban areas. The urban population indicated more sense in terms of ECN rather than the rural population as estimated at 1.08 and 0.2 respectively. They claimed that the increase in the consumption of electricity by the urban population was due to higher exposure to stocks of electrical appliances and electrical transportation. Meanwhile, Kaboli, Fallahpour, Kazemi, Selvaraj, and Rahim (2016) analyzed employment in modelling the industrial ELCD. According to Kaboli et al. (2016), employment referred to the number of employees that required additional ECN, such as the demand for space lightning, air conditioning and heating. The result showed that employment was found to be insignificant to explain industrial ELCD in Jordan. In Thailand, researcher argued that employment would have an effect on the rate of purchase of electrical appliances which increased ECN. The results showed that a unit change in employment level increased the consumption of electricity as calculated at 0.025 .

Furthermore, several studies, incorporated the number of consumers as one of the explanatory variables. For instance, Boogen et al. (2017) studied ECN in Greece covering the period from 1961 to 1986. During the investigation period, it was found that the coefficient of the number of electricity consumers was significant and played a very important role in the expansion of electricity usage in Greece. Author also confirmed that the number of electricity consumers was a proper determinant and showed a strong predictive in modelling the annual ECN in Northern Cyprus. In Iran, scholar found that the elasticity for the number of electricity consumers in industrial and agricultural sectors showed a positive sign as estimated at 0.24 to 1.2 respectively.

In another study, Tyagi \& Siddiqui, (2017); Bajjali and Shamayleh (2018) employed the number of electricity consumers to represent the quantity of firms that used electricity for the derivation of utility. The results of elasticity were found to be mixed. In the aggregate level and the commercial sector, the number of customers 
showed a positive sign as estimated at 0.07 and 0.62 respectively. Meanwhile, in the industrial and agricultural sectors, the number of consumers showed an opposite sign as both were estimated to be -1.71 and -0.93 respectively. This implied that electricity usage would increase in the aggregate level and the commercial sector but it would reduce in the industrial and agricultural sectors due to an increase in the number of consumers. In the same scholar found evidence that the number of electricity consumers had a significant impact on the sectoral ELCD in Pakistan from the period 1970 to 2006. The number of electricity consumers in the industrial and agricultural sectors indicated a positive sign as estimated at 2.42 and 2.21 respectively. However, none of the energy studies in Thailand have investigated the impact of consumers either on the aggregate level and sectoral ECN.

Furthermore, a small number of studies, such as Bajjali and Shamayleh (2018), applied electrical appliances in their ECN modelling. According to Bajjali and Shamayleh (2018), it was argued that the stock of electrical appliances was an important influencing factor to be considered in ECN model. For used urbanization as a proxy to capture the effects of technological changes in the stock of electrical appliances. The results showed that urbanization was an important variable in the long run, where elasticity was estimated at 3.91. Meanwhile, Bajjali and Shamayleh (2018) employed the value of imported electrical goods as a proxy for electrical appliances. This variable was used to investigate the usage of electrical goods and capital stock between the economic sectors in Pakistan. Thus, the results of electrical appliance elasticity was found to be significant and showed a positive sign in all sectors ranging from 0.23 to 1.69 . This indicated that an increase in the usage of electrical appliances would further increase the consumption of electricity.

In Iran, used fixed capital as a proxy for the stock of electrical appliances of the commercial sector and for the technology of the industrial and agricultural machinery. The author claimed that fixed capital was considered to explain the total investment of buildings and machinery in the commercial, industrial, public and agricultural sectors. Thus, it required the provision of more electrical appliances and equipment. The reason for such a relationship was that higher fixed capital in the form of appliances and machinery represented increasing investments in new electrical appliances and machinery. However, fixed capital was found to be insignificant to explain sectoral ELCD. In Thailand, none of the studies have tested the influence of the stock of electrical appliances on sectoral ELCD.

Other studies, such as Tasnim and Amin (2018) also considered different forms of energy or fuel as an alternative to electricity. This assumed that natural gas, oil, and diesel could be used as substitute forms of energy to electricity. However, this was not easily validated because electricity has unique characteristics. According to Akarsu (2017), electricity was the cleanest of all fuels and it was versatile and easily transferable. Thus, it was impossible or difficult for other fossil fuel processes to compete. For instance, employed natural gas as a substitute form of energy for ECN in Australia. It was found that natural gas was not a perfect substitute for electricity. Similarly, Tasnim and Amin (2018) found that natural gas price elasticity was insignificant to explain the ECN in rural and urban areas in Thailand. Moreover, author suggested that electricity was not a perfect substitute for other forms of energy during his study on the aggregate level and the sectoral ELCD in Pakistan. Pourazarm (2012) also found that substitute forms of energy, such as diesel, gas and fuel oil, had no substitution relationship with sectoral ELCD. These results highlighted that the elasticity of substitute energy was either inelastic or insignificant. Therefore, it can be concluded that the substitute price of energy is not appropriate to explain ECN.

\subsection{Theoretical Framework}

Theoretically, the demand for electricity is derived demand that comes from the demand for lighting, heating, cooling and others. In the study by Pourazarm (2012), ELCD by the different sectors, such as the industrial and agricultural sectors are modelled as the outcome of a cost minimization theory that is used by a firm in the production process. As a result, production by these sectors is considered to be a function of ELCD input and demand input of labour, capital and other inputs. Following the work by Pourazarm (2012), the behavioural equation of a firm's ELCD function is constructed from the production function as follows: 


$$
Y=\left(E_{D}, E_{S}, L, Q\right)
$$

Where $Y$ is the level of output and, L, and Q are the quantity of electricity, being substitute energy, labour and capital respectively. Minimization of production cost subject to the constraint of the production function presents the ELCD of the firm $\left(E_{D}\right)$ as follows:

$$
E_{D}=f\left(Y, E P_{e}, E P_{s}, E P_{l}, E P_{k}\right) \ldots
$$

where $E P_{\varepsilon}, E P_{s}, E P_{l}$, and, $E P_{k}$ are the price of electricity, being the substitute fuel, labour and capital respectively. For consumers, the power demand is the sum of the ECN of all firms in the industry: where is the ELCD of the industry. Therefore

$$
Y_{\theta}=f\left(\ddot{Y}, \ddot{E} P_{\theta}, \ddot{E} P_{s}, E \ddot{P}_{l}, E \ddot{P}_{k}\right)
$$

where $Y_{\theta}$ is the total output and $\ddot{E P_{\theta}}, \ddot{E} P_{s}, E \ddot{P}_{l}$ and,$E \ddot{P}_{k}$ are the average price of $E P_{\theta}, E P_{s}, E P_{l}$, and , $E P_{k}$ respectively for the whole industry. Let the functional form of demand assume constant elasticity, then:

$$
Y_{\theta}=f\left(\ddot{Y^{\vartheta}}, \ddot{E P}_{e}^{\alpha}, \ddot{E P}_{s}^{\beta}, E \ddot{P}_{l}^{\gamma}, E \ddot{P}_{k}{ }^{\rho}\right)
$$

By taking the log transformation from both sides of Equation (4), the ELCD function can be given by:

$$
y_{e}=f\left(\vartheta+\alpha_{e}+\beta_{s}+\gamma_{l}+\rho_{s}\right) .
$$

where the lowercase letters display the log value of the variables. As shown in Equation (5), the parameters $\alpha_{e}, \beta_{s}, \gamma_{l}$, and $\rho_{s}$ are estimates of the elasticity. Based on the theoretical and empirical reviews, this study considers representing income or output. Meanwhile, $\alpha_{e}$ represents the price of electricity, $\beta_{s}$ indicates the price of substitute fuel, $\gamma_{l}$, indicates the price of labour, and $\rho_{s}$ represents the price of capital. Note that the price of substitute energy is not included in this study since it does not significantly explain ELCD according to Bekhet and bt Othman (2011) and Jamil and Ahmad (2011). Moreover, due to the lack of data for, total employment will be considered in this series.

Therefore, this study will pool cross-section and time series data to examine the relationship between ECN, GDP, the price of electricity, the number of electricity consumers, employment and capital investment. The function of ECN can be written in the following equation:

$$
E C N=f(G D P+P R E+N O C N S+E M P L+C I N)
$$

Based on the ECN functions, the econometrical can be finally specified model as follows:

$$
E C N_{i t}=\alpha_{0}+\alpha_{1} G D P_{i t}+\alpha_{2} P R E_{i t}+\alpha_{3} N_{O C N S_{i t}}+\alpha_{4} E M P L_{i t}+\alpha_{5} C I N_{i t} \ldots(7)
$$

\section{Data and Method}

Secondary data are utilized in this study based on a balance panel consisting of the annual data for 11 years, from the period of 2007 until 2018. The data are gathered and verified from various sources After the panel series are found to be integrated at the same order at first difference, the next step is to test whether EC and the independent variables are cointegrated or whether there is the existence of stable long term relationship. Hence, the sectoral ELCD relationship will be examined using the panel cointegration approach suggested by Pedroni (1999). This procedure allows consistent and efficient estimation of the parameters in relatively small 
samples and also control for potential endogeneity of the regressors and serial correlation. In this study, panel cointegration tests proposed by Pedroni (1999) will be applied since he determines the suitability of the tests to be used in calculating the residuals from a cointegration regression after normalizing the panel statistics with correction terms.

Once the explanatory variables are cointegrated in the long run, then the model is estimated by adopting panel FMOLS techniques developed by Pedroni (1999). The purpose of FMOLS is to obtain long run cointegration relationship of the sectoral ECN model. This technique is used for estimating the cointegration vector in the dynamic panel data that allows considerable heterogeneity across individual sectors of the panel. The advantage of using this technique is that the group means estimator is behaving reasonably well even in a relatively small sample under a variety of scenarios Pedroni (1999).

\section{Results}

Correlation analysis is used to determine the direction and strength of the relationship between ECN with GDP, price of electricity, number of electricity consumers, employment and capital investment. As illustrated in Table 1, the results show that all variables, except the price of electricity, have a positive relationship with ECN. Moreover, GDP and the number of electricity consumers indicate the strongest relationship with ECN.

Table 1. Correlation Analysis

\begin{tabular}{|c|c|c|c|c|c|c|}
\hline & $\mathbf{1}$ & $\mathbf{2}$ & $\mathbf{3}$ & $\mathbf{4}$ & $\mathbf{5}$ & $\mathbf{6}$ \\
\hline ECN & 1.00 & & & & & \\
\hline & -- & & & & & \\
\hline GDP & 0.15 & 1.00 & & & & \\
\hline & $(0.41)$ & -- & & & & \\
\hline PRE & 0.20 & 0.13 & 1.00 & & & \\
\hline & $(0.27)$ & $(0.48)$ & -- & & & \\
\hline NOCNS & 0.26 & -0.13 & 0.41 & 1.00 & & \\
\hline & $(0.15)$ & $(0.46)$ & $(0.02)$ & -- & & \\
\hline EMPL & 0.03 & -0.12 & 0.43 & 0.03 & 1.00 & \\
\hline & $(0.87)$ & $(0.52)$ & $(0.01)$ & $(0.88)$ & -- & \\
\hline CIN & 0.311 & 0.03 & -0.23 & 0.31 & 0.13 & \\
\hline & $(0.01)$ & $(0.87)$ & $(0.52)$ & $(0.01)$ & $(0.88)$ & - \\
\hline
\end{tabular}

Econometric theory requires that all variables must be stationary conditions before performing cointegration tests. If non-stationary variables are used in the regression, the results will be misleading because of spurious regression. Therefore, it is a preliminary condition to test for unit root before proceeding to other econometric analysis. In this study, the LLC test was employed to perform the panel unit root test. This test was performed on both levels and at first difference for all variables.

Table 1. Panal Cointegration test Results

\begin{tabular}{|l|c|c|}
\hline \multicolumn{1}{|c|}{ Test } & Constant & Constant+Trend \\
\hline Panel v-Statistics & -1.926 & -2.8731 \\
\hline Panel $\rho$-Statistics & 0.07231 & 0.7632 \\
\hline Panel $t$-Statistics (non-parametric) & $-5.4322 * * *$ & $-8.843 * * *$ \\
\hline Panel $t$-Statistics (parametric) & $-6.3207 * * *$ & $-6.674 * * *$ \\
\hline Group $\rho$-Statistics & 3.212 & 4.423 \\
\hline Group $t$-Statistics (non-parametric) & $-7.762^{* * *}$ & $-9.262 * * *$ \\
\hline Group $t$-Statistics (parametric) & $-3.877^{* * *}$ & $-4.324 * * *$ \\
\hline
\end{tabular}


This section reports the results of the panel cointegration test based on Pedroni (1999). The residuals of the Pedroni cointegration test allow the ECN model to be determined whether there is an existence of the long run relationship among the variables that are not stationary. The procedure of the Pedroni cointegration test involves seven different test statistics, as discussed in previous section. If these statistic values are found to be statistically significant, this suggests that the null hypothesis of no cointegration can be rejected. Therefore, there is a presence of a cointegrating relationship among the variables in the ECN model. As illustrated in Table 2, the panel cointegration test contains the results of the panel statistics and the group statistics. In the panel statistics, if there is a common statistical value within the dimension, the model should be cointegrated. The null hypothesis stated that there is no common statistical value within the dimension, which also means that there is no cointegration in the ECN model. In the group statistics, the alternative hypothesis suggests that there is a significant individual statistical value between the sectors.

\section{Conclusion}

The price of electricity (PE) elasticity has mixed results throughout the sectors. For instance, the results of electricity price elasticity in the industrial and commercial sectors are significant at the five percent level but both sectors indicate a different sign. In the commercial sector, a one percent increase in electricity price causes a reduction in ECN by 0.39 percent. The negative sign in electricity price affirms the theory that price has an inverse relationship to consumption. The coefficient of electricity price elasticity is inelastic, which means that the commercial sector ECN is less responsive with respect to electricity price changes. Generally, electrical energy in the commercial sector is used for cooling and lighting where the lifetime of electrical appliances is relatively long. This implies a low response to electricity price changes. The result is consistent with the findings by Alter and Syed (2011) and Javid and Qayyum (2014) where they found price elasticity to be between the range of -1.83 to -0.26 .

In contrast, the electricity price elasticity in the industrial sector shows a positive sign. This indicates that a one percent increase in electricity price will increase the industrial sector's ECN by 0.37 percent. The result contradicts with the theory of demand law which explains that the price should have an opposite relationship to the quantity demanded. This suggests that increases in electricity tariff will give no impact on the industrial sector to reduce production; instead they continue to purchase electrical energy as a main input to run machinery operations as well as for cooling, heating and lighting in the production processes. This could be explained by the fact that the industrial sector enjoys the lowest electricity tariff as compared to other sectors in the economy due to high fuel subsidies by the government. The results are consistent only with the findings by Javid and Qayyum (2014). Moreover, electricity price elasticity in the mining and agricultural sectors is found to be insignificant.

The results of the number of electricity consumers (CONS) are statistically significant in the long run for all sectors. The sign of consumer elasticity in the commercial sector is elastic as estimated at 1.17 , but the mining and agricultural sectors are found to be inelastic as estimated at 0.86 and 0.84 , respectively. This means that the commercial sector's ECN is more responsive to changes in the number of electricity consumers rather than that of the mining and agricultural sectors', which is less responsive. The positive relationship between consumers and ECN, especially in the commercial sector, is consistent with the findings by Alter and Syed (2011), but in the agricultural sector it is consistent with that of Khan and Qayyum (2009). However, a number of electricity consumers have a negative relationship with the industrial sector's ECN, which is in line with the findings by Alter and Syed (2011). This indicates that with a one percent increase in the number of electricity consumers, the industrial sector's ECN is reduced by 0.17 percent, which could be explained by the lack of availability of sufficient electricity supply Alter and Syed (2011) for the derivation of utility. 


\section{References}

Acuña, G. (2017). Elasticidades de la demanda de agua en Chile.

Akarsu, G. (2017). Analyzing the impact of oil price volatility on electricity demand: the case of Turkey. Eurasian Economic Review, 7(3), 371-388.

Ali, A. (2016). The Impact of Electricity Outages on Households. https://www.semanticscholar.org/paper/The-impact-of-electricityoutages-on-households-Ali/57ced4bd2d8a05d3f1927f203947b7db58056b04

Alter, N., \& Syed, S. H. (2011). An empirical analysis of electricity demand in Pakistan. International Journal of Energy Economics and Policy, 1(4), 116-139.

Atalla, T. N., \& Hunt, L. C. (2016). Modelling residential electricity demand in the GCC countries. Energy Economics, 59, 149-158. http://doi.org/10.1016/j.eneco.2016.07.027

Bajjali, S. K., \& Shamayleh, A. Y. (2018). Estimating the determinants of electricity consumption in Jordan. Energy, 147, 1311-1320. http://doi.org/10.1016/j.energy.2018.01.010

Bekhet, H. A., \& bt Othman, N. S. (2011). Causality analysis among electricity consumption, consumer expenditure, gross domestic product (GDP) and foreign direct investment (FDI): Case study of Malaysia. Journal of economics and international finance, 3(4), 228-235. http://www.academicjournals.org/app/webroot/article/article1379674624_Bekhet\%20and\%20Othman.pdf

Boogen, N., Datta, S., \& Filippini, M. (2017). Dynamic models of residential electricity demand: Evidence from Switzerland. Energy Strategy Reviews, 18, 85-92. https://doi.org/10.1016/j.esr.2017.09.010

Buyinza, F., \& Kapeller, J. (2018). Household Electrification and Education Outcomes: Panel Evidence from Uganda: ICAE Working Paper Series. https://www.econstor.eu/bitstream/10419/193624/1/wp85.pdf

Caldara, D., Cavallo, M., \& Iacoviello, M. (2019). Oil price elasticities and oil price fluctuations. Journal of Monetary Economics, 103, 1-20. https://doi.org/10.1016/j.jmoneco.2018.08.004

Cialani, C., \& Mortazavi, R. (2018). Household and industrial electricity demand in Europe. Energy Policy, 122, 592-600. https://doi. $\operatorname{org} / 10.1016 /$ j.enpol.2018.07.060

Commander, S., Nikoloski, Z., \& Vagliasindi, M. (2015). Estimating the size of external effects of energy subsidies in transport and agriculture: The World Bank.

Dai, Y., \& Gao, H. O. (2016). Energy consumption in China's logistics industry: A decomposition analysis using the LMDI approach. Transportation Research Part D: Transport and Environment, 46, 69-80. https://doi.org/10.1016/j.trd.2016.03.003

Debnath, K. B., \& Mourshed, M. (2018). Forecasting methods in energy planning models. Renewable and Sustainable Energy Reviews, 88, 297-325. https://doi.org/10.1016/j.rser.2018.02.002

Diawuo, F. A., Baptista, P. C., \& Silva, C. A. (2018). Energy efficiency deployment: A pathway to sustainable electrification in Ghana. Journal of Cleaner Production, 186, 544-557.

Dudin, M.N., Frolova, E.E., Protopopova, O.V., Andrey Alievich Mamedov, A.A., Odintsov, S.V. (2019). Study of innovative technologies in the energy industry: nontraditional and renewable energy sources, Entrepreneurship and Sustainability Issues 6(4): 1704-1713. http://doi.org/10.9770/jesi.2019.6.4(11)

Feron, S. (2016). Sustainability of off-grid photovoltaic systems for rural electrification in developing countries: A review. Sustainability, 8(12), 1326.

Foster, J., Wagner, L., \& Liebman, A. (2015). Modelling the Electricity and Natural Gas Sectors for the Future Grid: Developing CoOptimisation Platforms for Market Redesign.

Gillingham, K., Rapson, D., \& Wagner, G. (2016). The rebound effect and energy efficiency policy. Review of Environmental Economics and Policy, 10(1), 68-88. https://doi.org/10.1093/reep/rev017

Haseeb, M., Kot, S., Hussain, H. I., \& Jermsittiparsert, K. (2019). Impact of Economic Growth, Environmental Pollution, and Energy Consumption on Health Expenditure and R\&D Expenditure of ASEAN Countries. Energies, 12(19), 3598.

Hassan, S. (2018). Long run energy demand and its determinants. 
Humbatova, S. I. O., Garayev, A.I.O., Tanriverdiev, S.M.O., Hajiyev, N.Q-O. 2019. Analysis of the oil, price and currency factor of economic growth in Azerbaijan. Entrepreneurship and Sustainability Issues, 6(3), 1135-1153. http://doi.org/10.9770/ jesi.2019.6.3(20)

Inglesi-Lotz, R., \& Pouris, A. (2016). On the causality and determinants of energy and electricity demand in South Africa: A review. Energy Sources, Part B: Economics, Planning, and Policy, 11(7), 626-636.

Inglesi-Lotz. (2019). Energy research and R\&D indicators: An LMDI decomposition analysis for the IEA Big 5 in energy research. Energy Policy, 133, 110940. http://doi.org/10.1016/j.enpol.2019.110940

Ivy-Yap, L., \& Bekhet, H. (2014). Modeling residential electricity consumption function in Malaysia: Time series approach. International Journal of Electrical, Electronic Science and Engineering, 8(3), 39-45.

Jamil, F., \& Ahmad, E. (2011). Income and price elasticities of electricity demand: Aggregate and sector-wise analyses. Energy Policy, $39(9), 5519-5527$.

Javid, M., \& Qayyum, A. (2014). Electricity consumption-GDP nexus in Pakistan: A structural time series analysis. Energy, $64,811-817$.

Kaboli, S. H. A., Fallahpour, A., Kazemi, N., Selvaraj, J., \& Rahim, N. (2016). An expression-driven approach for long-term electric power consumption forecasting. American Journal of Data Mining and Knowledge Discovery, 1(1), 16-28.

Khan, I., \& Qayyum, A. (2009). Performance evaluation of AODV and OLSR in highly fading vehicular ad hoc network environments. Paper presented at the 2009 IEEE 13th International Multitopic Conference.

Krutsyak, M. (2019). Forecasting demand on the Ukrainian electricity market using socio-economic variables. Economics, Management and Sustainability, 4(1). https://doi.org/10.14254/jems.2019.4-1.5

Kuiken, D., \& Más, H. F. (2019). Integrating demand side management into EU electricity distribution system operation: A Dutch example. Energy Policy, 129, 153-160.

Labandeira, X., Labeaga, J. M., \& López-Otero, X. (2017). A meta-analysis on the price elasticity of energy demand. Energy Policy, 102, 549-568.

Maree, G., 2017. Leading learners: A view from the trenches. International Journal of Innovation, Creativity and Change, 3(1): 13-25. Margaret, A.C. and G. Donna, 2017. Educational media: Potential impacts on tertiary students' mental health. International Journal of Innovation, Creativity and Change, 3(3): 61-88.

Masood, O., Tvaronavičienè, M., Javaria, K. 2019. Impact of oil prices on stock return: evidence from G7 countries. Insights into Regional Development, 1(2), 129-137. https://doi.org/10.9770/ird.2019.1.2(4)

Melas, V., Lisin, E., Tvaronavičienè, M., Peresadko, G., Radwański, R. (2017). Energy security and economic development: renewables and the integration of energy systems. Journal of Security and Sustainability Issues, 7(1), 133-139. https://doi.org/10.9770/ jssi.2017.7.1(11)

Mensah, J. T., Marbuah, G., \& Amoah, A. (2016). Energy demand in Ghana: A disaggregated analysis. Renewable and Sustainable Energy Reviews, 53, 924-935.

Mohd Hafiz Aswad, N. (2015). Analysis on the relationship between sectoral electricity consumption, economics performance and electricity price in Malaysia. Universiti Utara Malaysia.

Ngondya, D. J. (2018). Demand-side management framework for deregulated electricity markets. NM-AIST.

Null, S. (2018). Economic Water Demand Functions to Value Urban Water Scarcity along Utah's Wasatch Front. HydroShare. http:// www.hydroshare.org/resource/a6921 eef1 cbf4968b271d972bd997ab3

Omojolaibi, J. A., Mesagan, E. P., \& Oladipupo, T. D. (2016). The dynamics of electricity consumption and private investment in Thailand. Economic Issues, 21(Part 2), 33-51.

Panos, E., Densing, M., \& Volkart, K. (2016). Access to electricity in the World Energy Council's global energy scenarios: An outlook for developing regions until 2030. Energy Strategy Reviews, 9, 28-49. https://doi.org/10.1016/j.esr.2015.11.003

Pedroni, P. (1999). Critical values for cointegration tests in heterogeneous panels with multiple regressors. Oxford Bulletin of Economics and statistics, 61(S1), 653-670.

Polemis, M. L. (2016). New evidence on the impact of structural reforms on electricity sector performance. Energy Policy, $92,420-431$. 
Pourazarm, E. (2012). Electricity demand analysis in different sectors: a case study of Iran. https://ro.uow.edu.au/theses/3786/

Rezk, M.R., Radwan, A., Salem, N.M., Sakr, T.M., Tvaronavičienė, M. (2019). Foresight for sustainable energy policy in Egypt: results from a Delphi survey. Insights into Regional Development, 1(4), 357-369. https://doi.org/10.9770/ird.2019.1.4(6)

Rogalev, A., Komarov, I., Kindra, V., Zlyvk, O. (2018). Entrepreneurial assessment of sustainable development technologies for power energy sector. Enterpreneurship and Sustainability Issues, 6(1), 429-445. http://doi.org/10.9770/jesi.2018.6.1(26)

Sani, S., Mukhtar, S., \& Gani, I. M. (2017). Relationship Between Electricity Consumption, Manufacturing Output and Financial Development: A New Evidence From Thailand.

Smaliukienė, R.; Monni, S. (2019). A step-by-step approach to social marketing in energy transition. Insights into Regional Development, 1(1), 19-32. https://doi.org/10.9770/ird.2019.1.1(2)

Strielkowski, W., Lisin, E., Astachova, E. (2017). Economic sustainability of energy systems and prices in the EU. Entrepreneurship and Sustainability Issues, 4(4), 591-600. http://dx.doi.org/10.9770/jesi.2017.4.4(14)

Su, Y.-W. (2019). Residential electricity demand in Taiwan: Consumption behavior and rebound effect. Energy Policy, $124,36-45$.

Supian, K., \& Ab, N. (2018). The Role of Supplier, Top Management and Government in Halal Practices Integrity of Malaysian Food Business. International Journal of Asian Social Science, 8(8), 549-559.

Swenson, C. (2016). Empirical evidence on municipal tax policy and firm growth. International Journal of Public Policy and Administration Research, 3(1), 1-13. http://dx.doi.org/10.18488/journal.74/2016.3.1/74.1.1.13

Tasnim, A., \& Amin, S. B. (2018). Electricity Generation, Output, Trade Openness \& Foreign Direct Investment nexus in Bangladesh: An Empirical Analysis. Journal of Accounting, 8(3). https://zantworldpress.com/wp-content/uploads/2018/10/1.-Ayesha.pdf

Todorov, G. N., Volkova, E. E., Vlasov, A. I., \& Nikitina, N. I. (2019). Modeling energy-efficient consumption at industrial enterprises. International Journal of Energy Economics and Policy, 9(2), 10-18. https://doi.org/10.32479/ijeep.7376

Tvaronavičienè, M., Nesterova, K., Kováčik, V. (2017). Energy security and long-term energy efficiency: case of selected counties. Journal of Security and Sustainability Issues, 7(2), 349-357. https://doi.org/10.9770/jssi.2017.7.2(14)

Tyagi, S., \& Siddiqui, S. (2017). Yield Curve and Momentum Effects in Monthly US Equity Returns: Some Nonparametric Evidence. Asian Journal of Economics and Empirical Research, 4(2), 61-67. https://doi.org/10.20448/journal.501.2017.42.61.67

Vlasov, A.I., Shakhnov, V.A., Filin, S.S., Krivoshein, A.I. (2019). Sustainable energy systems in the digital economy: concept of smart machines. Entrepreneurship and Sustainability Issues, 6(4), 1975-1986. http://doi.org/10.9770/jesi.2019.6.4(30)

Vlasov, P., \& Kiseleva, A. (2017). Ideology and Distortions of the Entrepreneurial Concept. The Results of Conflict in Organizational Culture. International Journal of Emerging Trends in Social Sciences, 1(2), 90-96.

Widiastuti, T., Rizali, N., Anantanyu, S., \& Waluyo, S. E. (2017). Building Synergy Strategy “Cawas Lurik Centre” Association to Preserve the Existence of Crafting Business. International Journal of Emerging Trends in Social Sciences, 1(2), 97-103.

Wonyra, K. O. (2018). Industrialization and Economic Growth in Sub-Saharan Africa: The Role of Human Capital in Structural Transformation. Journal of Empirical Studies, 5(1), 45-54. http://doi.org/10.18488/journal.66.2018.51.45.54

Zafarullah, M. (2018). VAT and Accounting Issues and Solutions in UAE. International Journal of Social and Administrative Sciences, 3(1), 35-41. http://doi.org/10.18488/journal.136.2018.31.35.41

Zhang, W. B. (2018). Growth, Residential Distribution, and Land Price in an Integrated Solow's Growth and Alonso's Residential Model. Asian Themes in Social Sciences Research, 2(1), 23-31.

This work is licensed under the Creative Commons Attribution International License (CC BY).

http://creativecommons.org/licenses/by/4.0/ 